\author{
Military Technical College \\ Kobry Elkobbah, \\ Cairo, Egypt \\ April 3-5,2018
}

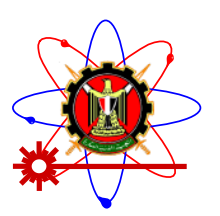

9th International Conference on Mathematics and

Engineering Physics (ICMEP-9)

\title{
Basic investigation of plasma glow discharge phenomena with modifiedbreakdown condition using aluminum and graphite disc electrodes
}

\author{
Samah Radwan ${ }^{a}$ and Mohamed Bourham ${ }^{\mathrm{b}}$ \\ ${ }^{a}$ Accelerators \& Ion Sources Department, Basic Nuclear Science Division, Nuclear Research Center, Atomic Energy Authority, P.N.13759 Cairo, \\ Egypt \\ ${ }^{b}$ North Carolina State University, College of Engineering, Department of Nuclear Engineering, Raleigh NC 27695, USA
}

\begin{abstract}
Experimentally, we study the effect of work function anode - cathode materials and their surface area on direct current glow discharge.Also, this effecthas been investigated using SRIM code. The different diameters for parallel discs anode - cathode and their materials at different atmospheric pressures were determined. Here, the six gas discharge cases of $7.5 \mathrm{~cm}$ and $9.5 \mathrm{~cm}$ anode - cathode electrodes diameters from aluminum and graphite have been investigated. Then, Paschen curve and the voltage - current characteristics were determined.
\end{abstract}

Keywords:Glow Discharge - Breakdown Voltage - Paschen Law- SRIM - Backscattered Ions.

\section{Introduction}

One of the best studied types of glow discharges is the glow direct current discharges in tubes $[1,2]$.The glow discharge source is used in the microelectronics industry for plasma etching [3], surface treatment [4], gas lasers [5], light source [6], also in analytical chemistry [7], biomedical science [8] and the pollution control [9].A glow discharge is characterized by its distinctive regions between the anode and cathode electrodes across the tube. The physical characteristics of these regions are depending on the parameters such as the discharge tube geometry, working gas pressure, gas type, cathode material, applied potential and discharge current [10]. The plasma discharges formed in atmospheric pressure with spatially uniform are desirable due to their potential industrial applications [11].

The plasma of low pressure glow discharge is created by applying a potential difference between two plate electrodes placed at certain distance. The discharge is maintained stable because of the equal degree of simultaneous ionization according to the continuous loss of electrons. Also, an additional electrons are produced due to the secondary emission from the cathode surface [12].Then, many ionization processes take place to produce a large number of charge carriers in the gas. 

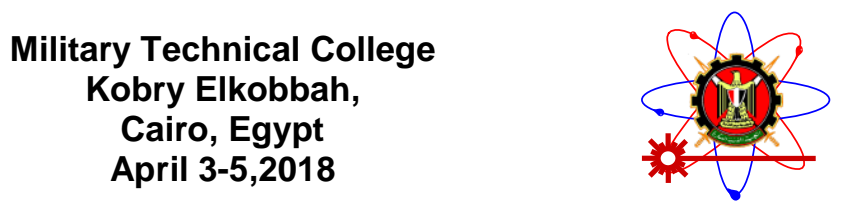
9th International Conference on Mathematics and
Engineering Physics (ICMEP-9)

Large amount of work carrying on the electric breakdown process because of its application in the accelerators, ion sources and plasma physics [13]. The electrical breakdown of a gas is possible only when a highly conductive channel is formed between the two electrodes translating from an insulator to a conductingstate. This transition occurs at minimum voltage which is called the breakdown voltage $\left(\mathrm{V}_{\mathrm{b}}\right)$. In Paschen's Law, the breakdown voltage between two electrodes is a function of pressure inside the chamber and the electrodes gap distance multiplied (Pd)according to the following relation[14]:

$$
\mathrm{V}_{\mathrm{b}}=\frac{\mathrm{Bpd}}{\ln \frac{(\mathrm{Apd})}{\ln \left(\frac{1}{\gamma}\right)}}(1)
$$

Where A, B are constantsof a particular gas and $\gamma$ is the secondary electron emission coefficient of the cathode. From equation (1), it is clear that $\mathrm{V}_{\mathrm{b}}$ of a gas depends only on Pd and cathode material [15]. Also, it depends on the charged and noncharged particles in the gas, the electrode configuration, the surface properties of the electrodes and the inner radius of discharge tubes. These factors are not considered in the Paschen's Law and might therefore responsible for the deviation between experimental and theoretical results [16].

In vacuum chamber, there are several free electrons due to cosmic rays. If a voltage is applied between the two electrodes, a free electron will begin to accelerate towards the anode. If the gas is sufficiently dense, the electron may collide with a neutral atom, causing ionization. When the resulting positive ion collides with the electrode and accelerates towards the cathode. Then, there is a finite probability $(\gamma)$ that a secondary electron will be emitted. This secondary electron may ionize more neutrals; the positive ions that result will stream towards the cathode. If an electron creates enough ions to release at least one additional secondary electron from the cathode, the process becomes self-sustaining and then the breakdown occurs.

The open sourceSRIM,Stopping and Range of Ions in Matter, which is a convenient tool to estimate the range of low energy particles in matter and based on the concept of nuclear and electronic stopping $[17,18]$.It is used to simulate the backscattered ions for the different gas discharge cases.

The aim of this experiment is to investigate experimentally the effect of two parameterson both Paschen's curve and the voltage - current characteristics which are the diameter and materialof the anode and the cathode electrodes. In which, we study the effect of $7.5 \mathrm{~cm}$ and $9.5 \mathrm{~cm}$ diameters of parallel discs for anode - cathode from aluminum and graphite materials.Furthermore, we can compare the backscattered ions between some cases of these gas dischargesusing SRIM.

\section{ExperimentalSetup}


Military Technical College

Kobry Elkobbah,

Cairo, Egypt

April 3-5,2018

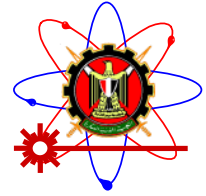

9th International Conference on Mathematics and

Engineering Physics (ICMEP-9)

It consists of a cylindrical Pyrex tube in which the two parallel discs anode - cathode and rotary pump are placed as shown in figure (1).This tube ispumped down to a base pressure up to the order of $10^{-3}$ torrusing rotary pump. This tube dimensionsare $50 \mathrm{~cm}$ length and $36.5 \mathrm{~cm}$ diameter. The diameters of electrodesare $7.5 \mathrm{~cm}$ and $9.5 \mathrm{~cm}$ with $0.7 \mathrm{~cm}$ thickness from graphite, $\mathrm{C}$, and aluminum, $\mathrm{Al}$, materials. The anode - cathode gap distance was fixed at $10 \mathrm{~cm}$. Two cylindrical plastic rubbers were used to close both sides of the chamber to prevent the leakage of gas as well as to insert the electrodes through them. One connection from one side is mounted to the rotary pump to evacuate the chamber to ultimate pressure $7.0 \times 10^{-2}$ Torr using thermocouple vacuum gauge. Also, one connection from the other side is the needle valve to control the air flow. The experiment was carried out under pressure ranged from $11.2 \times 10^{-2}$ to $8.1 \times 10^{-1}$ Torr.

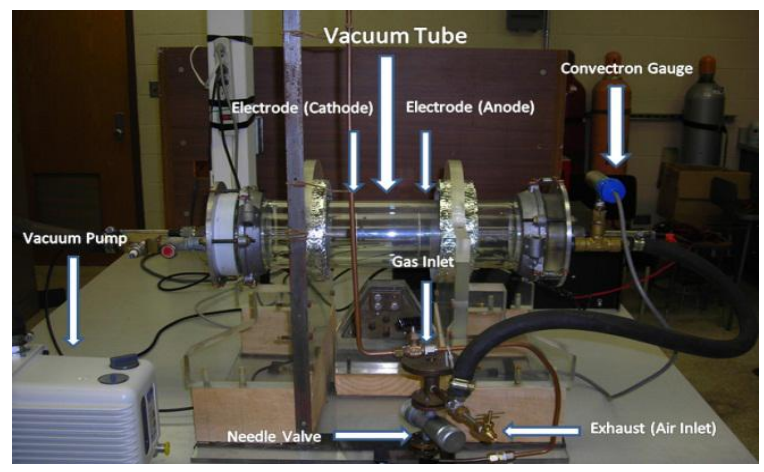

Fig. (1)Glow discharge setup.

The schematic diagram of the discharge system is shown in fig. (2). Figure (3) shows the electrical circuit in which the anode is connected to $5 \mathrm{kV}$ positive power supply for initiating the discharge (glow discharge) between the anode and cathode. The cathode is connected to ground. The ammeter, A, is used to measure the discharge current between the anode and the cathode, while a voltmeter, $\mathrm{V}$, is used to measure the discharge voltage between them.
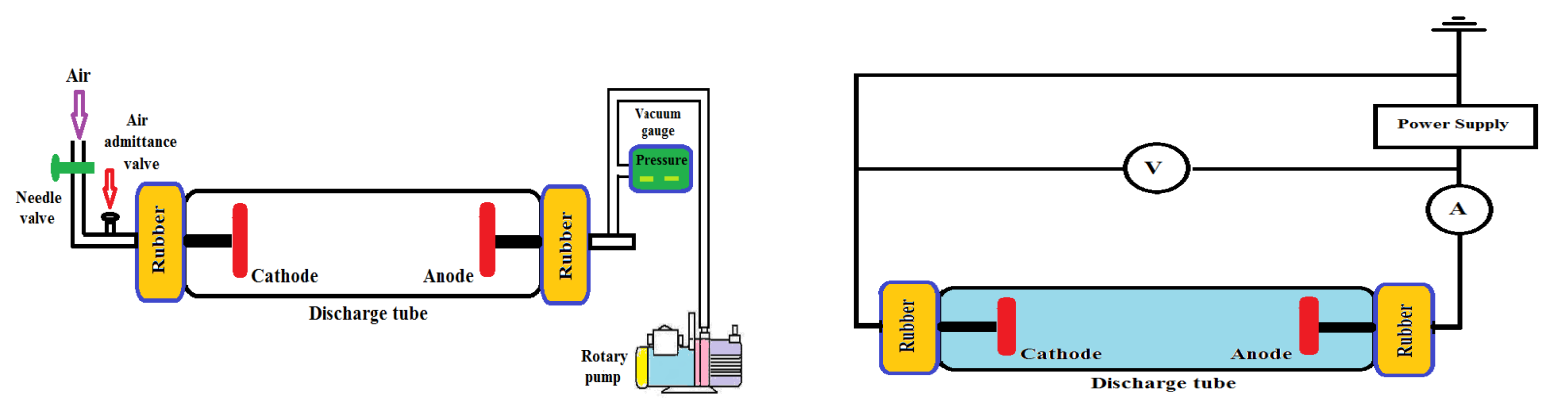

Fig.(2) Schematic drawing of the experimental setup.Fig.(3) Electrical circuit of the experiment.

In this paper, the different gas discharge cases have been studied as shown in table (1). 

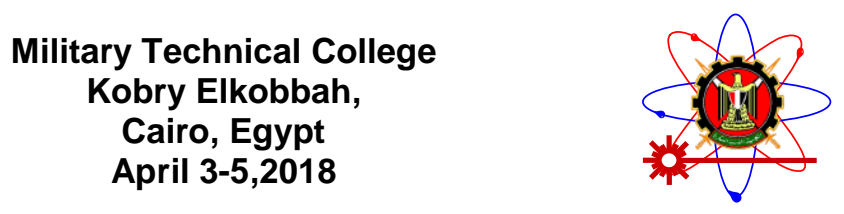

9th International Conference on Mathematics and

Engineering Physics (ICMEP-9)

\begin{tabular}{|c|c|c|c|c|c|c|c|c|}
\hline $\begin{array}{c}\text { discharge } \\
\text { case }\end{array}$ & \multicolumn{2}{|c|}{ Anode } & \multicolumn{2}{c|}{ Cathode } & \multicolumn{2}{c|}{ Anode } & - & \\
\hline 1 & diameter $7.5 \mathrm{~cm}$ & $\mathrm{Al}$ & diameter $7.5 \mathrm{~cm}$ & $\mathrm{Al}$ & - & & - & \\
\hline 2 & diameter $9.5 \mathrm{~cm}$ & $\mathrm{Al}$ & diameter $9.5 \mathrm{~cm}$ & $\mathrm{Al}$ & - & & $\mathrm{Ade}$ \\
\hline 3 & diameter $9.5 \mathrm{~cm}$ & $\mathrm{Al}$ & diameter $9.5 \mathrm{~cm}$ & $\mathrm{C}$ & diameter $9.5 \mathrm{~cm}$ & $\mathrm{C}$ & diameter $9.5 \mathrm{~cm}$ & $\mathrm{Al}$ \\
\hline 4 & diameter $7.5 \mathrm{~cm}$ & $\mathrm{Al}$ & diameter $9.5 \mathrm{~cm}$ & $\mathrm{C}$ & diameter $9.5 \mathrm{~cm}$ & $\mathrm{C}$ & diameter $7.5 \mathrm{~cm}$ & $\mathrm{Al}$ \\
\hline
\end{tabular}

Table (1): Gas discharge cases for the different anode and cathode diameters and their materials.

\section{SRIM simulation}

The SRIM code is based on a Monte Carlo simulation method where the binary collision approximation with a random selection of the impact parameter of the next colliding ion is used. SRIM and TRIM (Transport of Ions in Matter) are both useful in evaluation of material response to incident particles [19].There are a number of mechanisms operate to slow the ion, dissipate the energy if an ion is incident on a solid target material and subdivided into the nuclear and electronic energy losses [18]. Nuclear energy transfer occurs as the result of elastic collisions in whichthe energy is imparted from the incident ion to the target atom by momentum transfer. Electronic energy losses occur as the result of inelastic scattering events in which the ion electrons interact with that of the target atoms. Some ions might have a strong collision near the surface of the target and may be backscattered back out of the target surface. These ions called backscattered ions which have a trajectory that exits the target back through its surface, after one or more target collisions.

Figure (4) shows the comparison of backscattered ions versus the breakdown voltage, $\mathrm{V}_{\mathrm{b}}$, for $7.5 \mathrm{~cm}$ and $9.5 \mathrm{~cm}$ diameters $\mathrm{Al}$ anode and cathode. It is clear that backscattered ions for $7.5 \mathrm{~cm}$ and $9.5 \mathrm{~cm}$ diameters are identical after $\left(\mathrm{V}_{\mathrm{b}}\right)_{\min }$. They are different before $\left(\mathrm{V}_{\mathrm{b}}\right)_{\min }$, depending on $\left(\mathrm{V}_{\mathrm{b}}\right)_{\min }$ for $7.5 \mathrm{~cm}$ and $9.5 \mathrm{~cm}$ diameters anode and cathode that are $463 \mathrm{~V}$ and $523 \mathrm{~V}$ respectively. Backscattered ions increased by decreasing $\mathrm{V}_{\mathrm{b}}$ until reaching $\left(\mathrm{V}_{\mathrm{b}}\right)_{\text {min }}$ and then decreased by increasing $\mathrm{V}_{\mathrm{b}}$.

Figure (5) shows the comparison of backscattered ions versus the breakdown voltage, $\mathrm{V}_{\mathrm{b}}$, for the two gas discharge cases of the same diameters $(9.5 \mathrm{~cm}) \mathrm{Al}$ anode - Alcathode and $\mathrm{Al}$ anode - $\mathrm{C}$ cathode. It is clear that backscattered ions for Al anode - $\mathrm{Al}$ cathode are high than the another case. This is due to the work function of $\mathrm{Al}$ is lower than $\mathrm{C}$. But the same behavior that backscattered ions increase by decreasing $\mathrm{V}_{\mathrm{b}}$ until reaching $\left(\mathrm{V}_{\mathrm{b}}\right)_{\min }$ and then decreased by increasing $\mathrm{V}_{\mathrm{b}}$. This is due to after $\left(\mathrm{V}_{\mathrm{b}}\right)_{\min }$, higher gas pressure, more collisions will take place in the electron path between the electrodes. So that the electron is not always being accelerated by the electric field, always travelling back towards the cathode and decelerated forming small number of backscattered ions. 
Military Technical College

Kobry Elkobbah,

Cairo, Egypt

April 3-5,2018

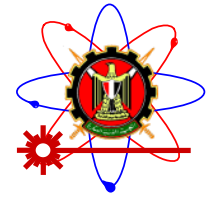

9th International Conference on Mathematics and

Engineering Physics (ICMEP-9)
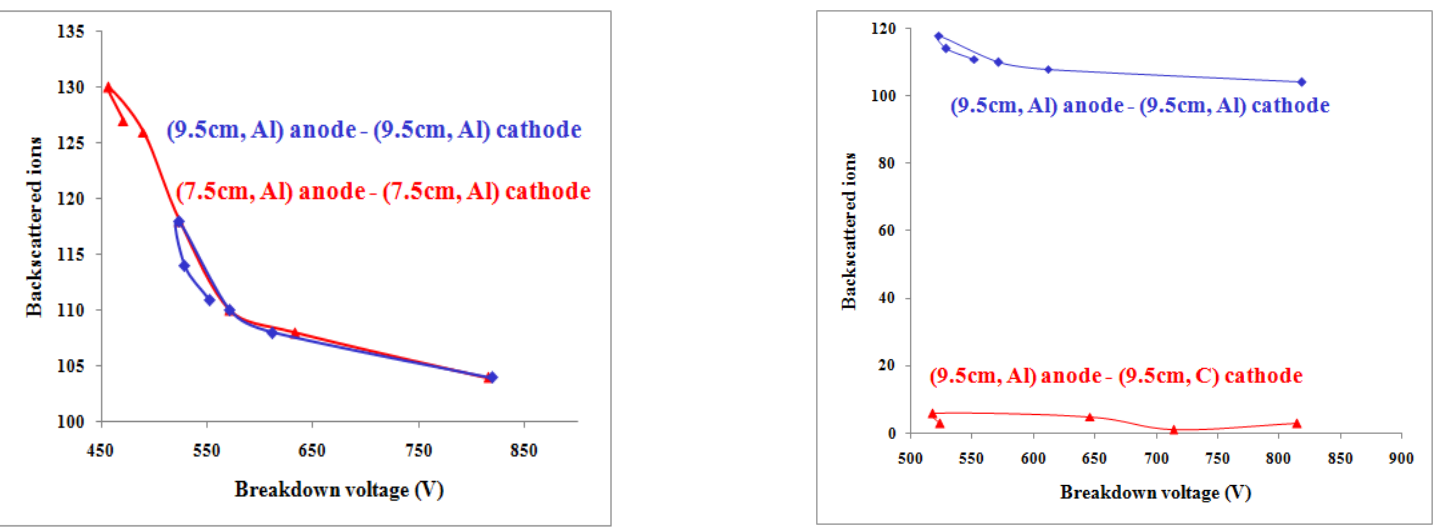

Fig.(4) Backscattered ions versus breakdown Fig.(5) Backscattered ions versus breakdown voltage voltage $\left(V_{b}\right)$ for $7.5 \mathrm{~cm}, 9.5 \mathrm{~cm}$ diameters for $\mathrm{Al}\left(\mathrm{V}_{\mathrm{b}}\right)$ for $9.5 \mathrm{~cm}$ diameters $\mathrm{Al}$ anode- $\mathrm{C}$ cathode and $\mathrm{Al}$ anode and cathode.anode and cathode.

\section{Results and discussions}

\subsection{Paschen curve}

The breakdown in DC discharges is usually described by the standard Townsend's theory [20]. It is represented by a Paschen curve in which the breakdown voltage, $V_{d}$, dependence on the product of gas pressure, $\mathrm{P}$, and gap electrodes distance, $\mathrm{d}$ [21]. The parameter Pd is a scaling parameter proportional to the number of collisions over a unit distance. In this respect, a typical sharp increase of $\mathrm{V}_{\mathrm{d}}$ at low $\mathrm{Pd}$ can be explained by the need to compensate for a small number of collisions. At high $\mathrm{Pd}$, due to a large number of collisions, $\mathrm{V}_{\mathrm{d}}$ is increased to enhance energy gain between collisions, so that the mean free path becomes shorter and the energy gained between two collisions becomes smaller.

Figure (6) shows the comparison of $\mathrm{Pd}$ (torr.cm) versus $\mathrm{V}_{\mathrm{b}}(\mathrm{V})$ atthe same diameters of $7.5 \mathrm{~cm}$ and $9.5 \mathrm{~cm}$ for $\mathrm{Al}$ anode - cathode. It is seen that the minimum breakdown voltage, $\left(\mathrm{V}_{\mathrm{b}}\right)_{\min }$, values are $463 \mathrm{~V}$ and $548 \mathrm{~V}$ at $(\mathrm{pd})_{\min }$ of 1.25 and 1.76 (torr.cm) for the discharge cases with diameter $7.5 \mathrm{~cm}$ and $9.5 \mathrm{~cm}$ anode - cathode respectively.

Figure (7) shows the comparison of Pd (torr.cm) versus $V_{b}(V)$ at the same diameter of $9.5 \mathrm{~cm}$ for $\mathrm{Al}$ anode $-\mathrm{C}$ cathode and $\mathrm{C}$ anode $-\mathrm{Al}$ cathode. It is seen that $\left(\mathrm{V}_{\mathrm{b}}\right)_{\min }$ values are $504 \mathrm{~V}$ and $486 \mathrm{~V}$ at (pd) $\min$ of 1.0 and 1.5(torr.cm) for the discharge cases $\mathrm{Al}$ anode - $\mathrm{C}$ cathode and $\mathrm{C}$ anode - $\mathrm{Al}$ cathode respectively. Also, the discharge case $\mathrm{Al}$ anode - $\mathrm{C}$ cathode has higher $\mathrm{V}_{\mathrm{b}}$ values than another case.

Figure (8) shows the comparison of $\mathrm{Pd}$ (torr.cm) versus $\mathrm{V}_{\mathrm{b}}(\mathrm{V})$ at $7.5 \mathrm{~cm}$ diameter of $\mathrm{Al}$ anode and $9.5 \mathrm{~cm}$ diameter of $\mathrm{C}$ cathode and the reverse polarity. It is seen that $\left(\mathrm{V}_{\mathrm{b}}\right)_{\min }$ values are $418 \mathrm{~V}$ and $570 \mathrm{~V}$ at $(\mathrm{pd})_{\min }$ of 1.17 and 1.78 (torr.cm) for the discharge cases $9.5 \mathrm{~cm}$ diameter of $\mathrm{C}$ anode 
Military Technical College

Kobry Elkobbah,

Cairo, Egypt

April 3-5,2018

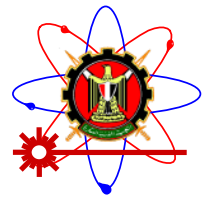

9th International Conference on Mathematics and

Engineering Physics (ICMEP-9)

and $7.5 \mathrm{~cm}$ diameter of $\mathrm{Al}$ cathode and its reverse polarity respectively. Also, the discharge case of $9.5 \mathrm{~cm}$ diameter for $\mathrm{C}$ anode and $7.5 \mathrm{~cm}$ diameter for $\mathrm{Al}$ cathode has higher $\mathrm{V}_{\mathrm{b}}$ values than another case.
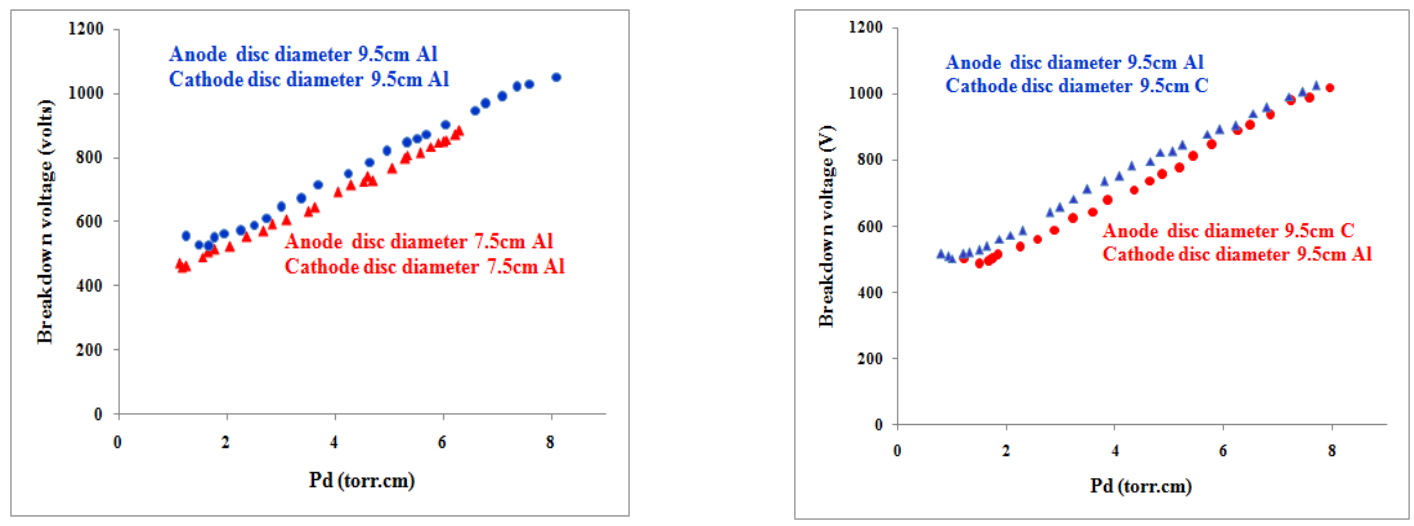

Fig. (6) Pd versus $V_{b}$ at $7.5 \mathrm{~cm}$ and $9.5 \mathrm{~cm}$ diametersFig. (7) $P d$ versus $V_{b} a t 9.5 \mathrm{~cm}$ diameter for $\mathrm{Al}$ for Alanode - cathode.anode-C cathode and the reversepolarity.

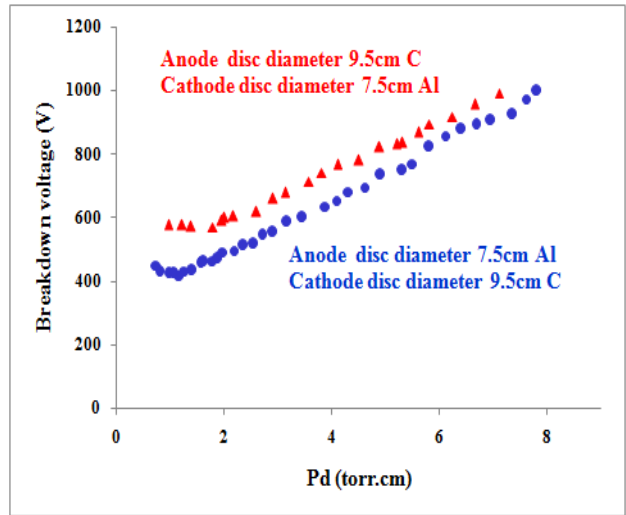

Fig. (8) Pd versus $V_{b}$ at $9.5 \mathrm{~cm}$ diameterof Canode- $7.5 \mathrm{~cm}$ diameterof $\mathrm{Al}$ cathode and the reverse polarity.

Initially $\mathrm{V}_{\mathrm{B}}$ decreases with increase in $\mathrm{Pd}$, reaching to the minimum value and then begins to increase [22].It is obvious that near $\left(\mathrm{V}_{\mathrm{b}}\right)_{\mathrm{min}}$, the density is low and then there are relatively few collisions. In fact, an electron does not necessarily ionize a molecule during collision, even if its energy exceeds the molecule ionization energy. The electrons have a finite chance of ionizing, which depends upon its energy. If the density and hence the number of collisions is decreased, the breakdown can occur only if the chance of ionizing is increased, and this accounts for the increase in voltage to the left of the minimum. Before $\left(V_{b}\right)_{\min }$ of Paschen's curves, $V_{b}$ decreases fast by increasing Pd,due to the increase in collision frequency. As a result ofthe increasing in the number of collisions between the electrons and neutral atoms or molecules. If the density is fixed, the breakdown to the left side of the minimum occurs more readily (i.e. at lower voltage) at longer distances. Butafter $\left(\mathrm{V}_{\mathrm{b}}\right)_{\min }, \mathrm{V}_{\mathrm{B}}$ increases slowly with the increase of $\mathrm{Pd}$, means that the 
Military Technical College

Kobry Elkobbah,

Cairo, Egypt

April 3-5,2018

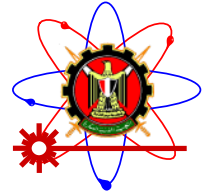

9th International Conference on Mathematics and

Engineering Physics (ICMEP-9)

ionization crosssection increases. Therefore, the electrons need more energy to breakdown the discharge gap, resulting in an increase of the breakdown voltage [23].

Finally, we make the comparison of $\mathrm{Pd}$ (torr.cm) versus $\mathrm{V}_{\mathrm{b}}(\mathrm{V})$ for all the gas discharge cases as shown in figure (9). It is clear that at $9.5 \mathrm{~cm}$ diameter of $\mathrm{C}$ anode and $7.5 \mathrm{~cm}$ diameter of $\mathrm{Al}$ cathode has the lowest $\mathrm{V}_{\mathrm{b}}$ values. Furthermore, the two gas discharge cases at the same diameters of $9.5 \mathrm{~cm}$ for ( $\mathrm{Al}$ anode - Ccathode, $\mathrm{Al}$ anode - $\mathrm{Al}$ cathode) and $7.5 \mathrm{~cm}$ diameter for $\mathrm{Al}$ anode $9.5 \mathrm{~cm}$ diameter for $\mathrm{C}$ cathode are nearly the highest $\mathrm{V}_{\mathrm{b}}$ values. The two remaining gas discharge cases at $7.5 \mathrm{~cm}$ diameters for $\mathrm{Al}$ anode - cathode and $9.5 \mathrm{~cm}$ diameters for $\mathrm{C}$ anode - $\mathrm{Al}$ cathode nearly have the same $V_{b}$ values in between the other cases.

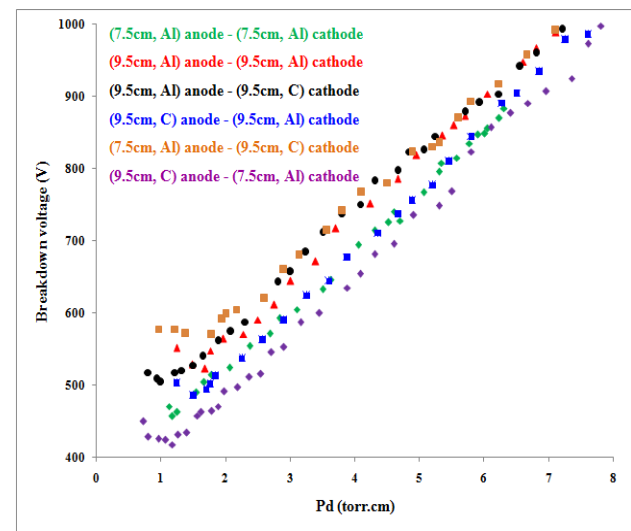

Fig. (9) Comparison of $P d$ versus $V_{b}$ for all the gas discharge cases.

\subsection{Voltage - current characteristics of the discharge}

Figure (10)shows the breakdown voltage, $\mathrm{V}_{\mathrm{b}}$, versus the discharge current, $\mathrm{I}_{\mathrm{d}}$, atthe same diameters of $7.5 \mathrm{~cm}$ and $9.5 \mathrm{~cm}$ for $\mathrm{Al}$ anode - cathode. It is clear that the discharge current increases by decreasing the breakdown voltage until reaching $\left(\mathrm{V}_{\mathrm{b}}\right)_{\min }$. After $\left(\mathrm{V}_{\mathrm{b}}\right)_{\min }$, the discharge current increases by increasing the breakdown voltage(positive resistance). For $7.5 \mathrm{~cm}$ diameter $\mathrm{Al}$ anode - cathode has higher discharge current values than another case.

Figure (11) shows the breakdown voltage, $V_{b}$, versus the discharge current, $I_{d}$, atthe same diameter of $9.5 \mathrm{~cm} \mathrm{Al}$ anode - $\mathrm{C}$ cathode and the reverse polarity. It is clear that the discharge current increases by decreasing the breakdown voltage until reaching $\left(\mathrm{V}_{\mathrm{b}}\right)_{\min }$. After $\left(\mathrm{V}_{\mathrm{b}}\right)_{\min }$, the discharge current increases by increasing the breakdown voltage. For $\mathrm{Al}$ anode - $\mathrm{C}$ cathode gives higher values of discharge current than the reverse polarity.

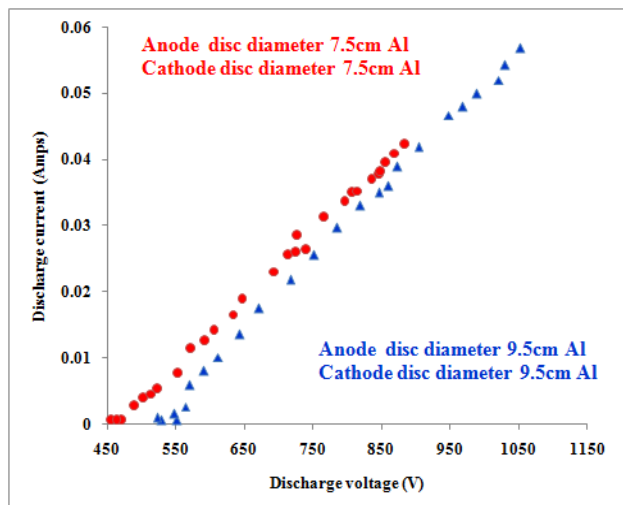
the

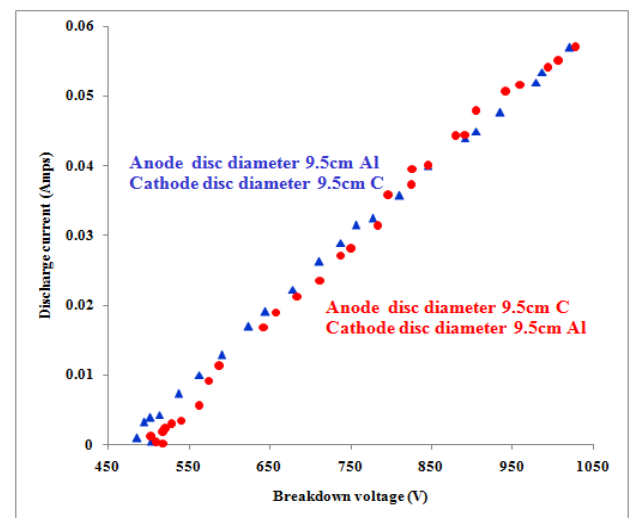

Figure

shows 
Military Technical College

Kobry Elkobbah,

Cairo, Egypt

April 3-5,2018

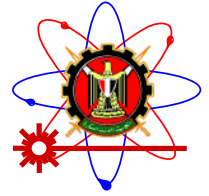

9th International Conference on Mathematics and

Engineering Physics (ICMEP-9)

breakdown voltage, $V_{b}$, versus the discharge current, $I_{d}$, at $9.5 \mathrm{~cm}$ diameter for $C$ anode $-7.5 \mathrm{~cm}$ diameter for $\mathrm{Al}$ cathode and the reverse polarity. It is clear that the discharge current increases by decreasing the breakdown voltage until reaching the $\left(\mathrm{V}_{\mathrm{b}}\right)_{\min }$. After $\left(\mathrm{V}_{\mathrm{b}}\right)_{\min }$, the discharge current increases by increasing the breakdown voltage. For $9.5 \mathrm{~cm}$ diameter ofC anode $-7.5 \mathrm{~cm}$ diameter of $\mathrm{Al}$ cathode gives higher values of discharge current than the reverse polarity.

Fig. (10) $V_{b}$ versus $I_{d}$ for $7.5 \mathrm{~cm}$ and $9.5 \mathrm{~cm}$ diameter Fig. (11) $V_{b}$ versus $I_{d}$ for $9.5 \mathrm{~cm}$ diameter $A l$ anode Alanode - cathode.- $\mathrm{C}$ cathode and the reverse polarity.

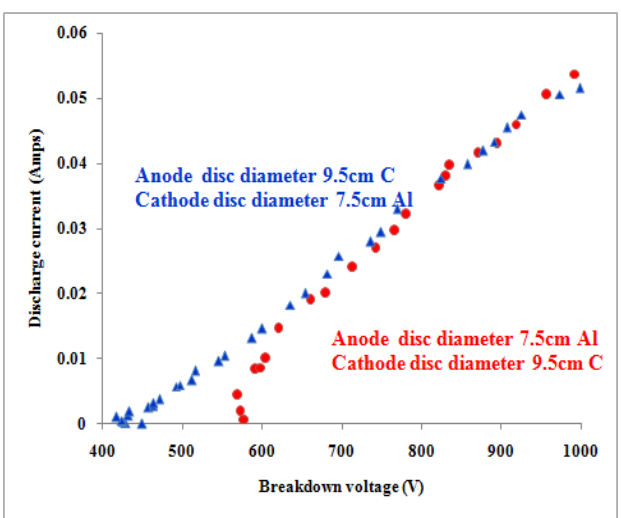

Fig. (12) $V_{b}$ versus $I_{d}$ for $9.5 \mathrm{~cm}$ diameterC anode $-7.5 \mathrm{~cm}$ diameter $A l$ cathode and the reverse polarity.

Finally, we make the comparison of voltage - current characteristics for all the gas discharge cases.Figure (13) shows the breakdown voltage, $V_{b}$, versus the discharge current, $I_{d}$, for all the gas discharge cases. It is clear that at the same diameters of $9.5 \mathrm{~cm}$ for $\mathrm{Al}$ anode $-\mathrm{C}$ cathode has the lowest discharge current values.Furthermore, at $9.5 \mathrm{~cm}$ diameter for $\mathrm{C}$ anode $-7.5 \mathrm{~cm}$ diameter for $\mathrm{Al}$ cathode,the same diameters of $9.5 \mathrm{~cm}$ for Canode - $\mathrm{Al}$ cathode and the same diameters of $7.5 \mathrm{~cm}$ for $\mathrm{Al}$ anode - cathode are nearly the highest discharge current values. The two remaining gas discharge cases at $7.5 \mathrm{~cm}$ diameterfor $\mathrm{Al}$ anode $-9.5 \mathrm{~cm}$ diameter for Ccathode and its reverse polaritynearly have the same discharge current values in between the other cases. 

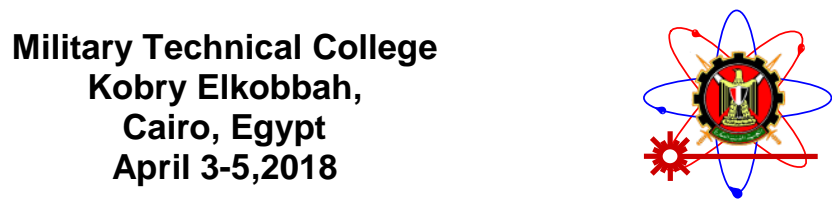

9th International Conference on Mathematics and

Engineering Physics (ICMEP-9)

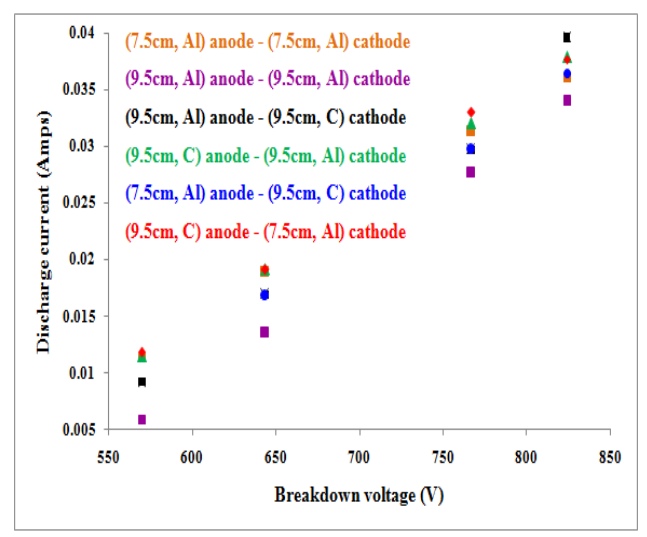

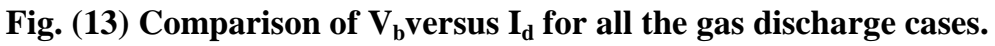

Due to the electrons have sufficient energy to generate visible light by the excitation collisions with the plasma carrier gas, then the luminous glow is produced. Since there is a continuous loss of electrons and ions, there must be an equal degree of ionization going on to maintain the steady state. The energy is being continuously transferred out of the discharge and hence the energy balance must be satisfied as well. The electrons absorb energy from the field by accelerating, ionize some atoms, and the process becomes continuous. Additional electrons must be produced by secondary electron emission from the cathode. These are very important to maintaining a sustainable discharge.

Figure (14) shows the pictures of (a- $7.5 \mathrm{~cm}$ diameters for $\mathrm{Al}$ anode and cathode),(b- $7.5 \mathrm{~cm}$ diameter for $\mathrm{Al}$ anode $-9.5 \mathrm{~cm}$ diameter for $\mathrm{C}$ cathode)plasma expanding in the cylindrical discharge tube at pressure 3.0Torr.
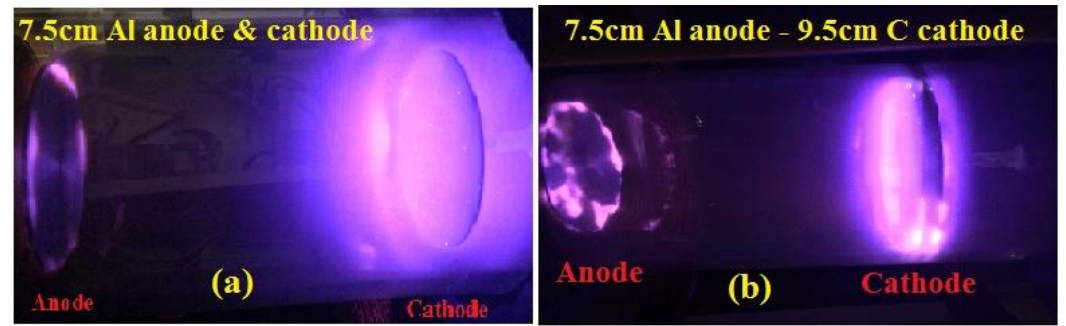

Fig. (14) Pictures of (a- $7.5 \mathrm{~cm}$ diameters Al anode and cathode), (b- $7.5 \mathrm{~cm}$ diameter Al anode $-9.5 \mathrm{~cm}$ diameter $\mathrm{C}$ cathode) plasma expanding in the cylindrical discharge tube at pressure 3.0Torr.

It is clear that there is a high light formed due to the plasma formation.However the resulting positive ion collides with the electrode and accelerates towards the cathode, so that it gives high light surrounding the cathode. The light originates from photons emitted by radiated relaxation of the excited meta-stable atoms and from excited ions. The accelerated electronstowards the cathode's sheath, gain enough energy to excite high energy levels of and near the cathode jaws [24]. 
Military Technical College

Kobry Elkobbah,

Cairo, Egypt

April 3-5,2018

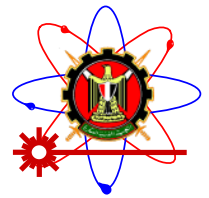

9th International Conference on Mathematics and

Engineering Physics (ICMEP-9)

\section{Conclusions}

In this work, the cathode plays an important role in the gas discharges by supplying electrons for the initiation, sustainableand completion of a discharge.

Using SRIM, the comparison of backscattered ions versus $\mathrm{V}_{\mathrm{b}}$ at different diameters for low work function materials anode - cathode and large diameter low/high work function anode - high/low work function cathode. It is concluded that backscattered ions for the gas discharge cases at different diameters for low work function are identical after $\left(\mathrm{V}_{\mathrm{b}}\right)_{\min }$. They are different before $\left(\mathrm{V}_{\mathrm{b}}\right)_{\text {min }}$, depending on their $\left(\mathrm{V}_{\mathrm{b}}\right)_{\text {min }}$. Also, at the same diameter for the same anode and cathode materials with low work function gives higher backscattered ions than that for low work function anode - high work function cathode materials.

From Paschen's curve, it is concluded that at large diameter for low work function materials of anode and cathode gives higher $V_{b}$ than small diameter of the same material electrodes. In case of large diameters for low anode and high cathode work functionmaterials gives higher $\mathrm{V}_{\mathrm{b}}$ than its reverse polarity. Also, at large diameter for high anode - small diameter for low cathode work function materials gives higher $\mathrm{V}_{\mathrm{b}}$ than its reverse polarity. Finally, from the comparison between all the gas discharge cases. It is obvious that, at large diameter for high anode - small diameter for low cathode work function materials has the lowest $\mathrm{V}_{\mathrm{b}}$ values. Furthermore, at large diameter for (low anode - high cathode),(low anode and cathode) and small diameter for low anode - large diameter for high cathode work function materials are nearly the highest $\mathrm{V}_{\mathrm{b}}$ values.At small diameters for low anode and cathode work function materials and large diameters for high anode - low cathode work function materials nearly have the same $V_{b}$ valuesplacing in the middle region between the other gas discharge cases.

From voltage - current characteristics, it is concluded that at large diameters for low anode - high cathode work function materials gives higher $\mathrm{I}_{\mathrm{d}}$ values than that for high anode - low cathode. In case of large diameter for high anode - small diameter for low cathode work function materials giveshigher $I_{d}$ values than small diameter for low anode - large diameter for high cathode work function materials. Also, at the same large diameters for low anode - high cathode work function materials giveshigher $I_{d}$ values than that of high anode - low cathode. Finally, from the comparison between all the gas discharge cases. It is obvious that, at the same large diameters for low anode - high cathode work function materials has the lowest $\mathrm{I}_{\mathrm{d}}$ values. Furthermore, at large diameter for high anode - small diameter for low cathode work function materials, the same large diameters for high anode - low cathode and the same small diameters for low anode and cathode work function materials are nearly the highest $I_{d}$ values.

\section{References}

[1] Yu. P. Raizer, "Physics of the Gas Discharge", Nauka, Moscow, (1987); Springer-Verlag, Berlin, 1991. 

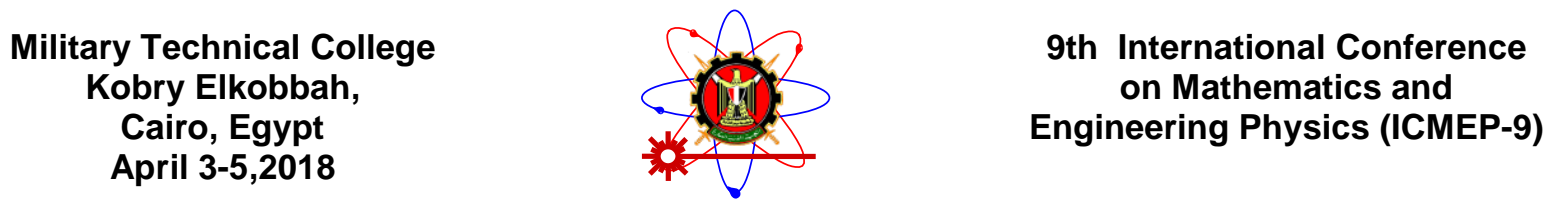

[2] G. G. Lister, "Low-pressure gas discharge modelling", J. Phys. D, 25, 1649, 1992.

[3] J. K. OlthoffandK. E. Greenberg, "The Gaseous Electronics Conference RF Reference Cell - An Introduction",J. Res. Natl. Inst. Stand. Technol., 100, 327, 1995.

[4] K. N. Pandiyaraj, "Low pressure DC glow discharge air plasma surface treatment of polyethylene film (PE) for improvement of adhesive properties", Plasma Sci. Technol., 15, 56, 2013.

[5]S. J. Choi and J. J. Yoh, "Laser - induced plasma peculiarity at low pressures from the elemental lifetime perspectives", The International Online Journal of Optics, 19, 23097-23103, 2011.

[6] D. Uhrlandt, "Investigating the plasma chemistry for the synthesis of carbon nanotubes/nanofibres in an inductively coupled plasma - enhanced CVD system: the effect of processing parameters", Journal of Physics D: Applied Physics, 38, 2005.

[7] S.Manolache, "Some Terpenes and related derivatives synthesized in cold plasma systems", Molecules,2, 158-164, 1997.

[8] O.Kyllan andF.Rossi, "Sterilization and decontamination of medical instruments by low pressure plasma discharges", Journal of Physics D: Applied Physics, 42, 8, 2009.

[9] J. S. Chang, "Physics and chemistry of plasma pollution control technology", Plasma Sources Science and Technology, 17, 4, 2008.

[10] M. A. Hassouba andE. A. Mehanna, "Electrical characteristics of (N2-H2) gas mixture DC glow discharge", International Journal of Physical Sciences, 713-721, 4, 2009.

[11] E. E. Kunhardt,"Generation of large-volume, atmospheric-pressure, nonequilibrium plasmas", IEEE Trans. Plasma Sci., 28, 189, 2000.

[12] A. Grill, "Cold Plasma in Material Fabrication from Fundamental to Applications", IEEE Press, New York, 1993.

[13]A. Bogaerts, E. Neyts, R. Gijbels and J. van der Mullen, "Gas discharge plasmas and their applications",Spectrochim. Acta, Part B, 57, 609, 2002.

[14] F. Paschen, "Ueber die zum Funkenübergang in Luft, Wasserstoff und Kohlensäure bei verschiedenen Drucken erforderliche Potentialdifferenz (On the potential difference required for spark initiation in air, hydrogen, and carbon dioxide at different pressures)", Annalen der Physik, 273, 5, 69-75, 1889.

[15] M. Quitzau, M. Wolter andH. Kersten, "Plasma treatment of Polyethylene powder particles in a hollow cathode glow discharge", Plasma Process. Polym.,6, 5392, 2009.

[16] D.Fliegel andD.Gunther,"Electrical characteristics of a millisecond pulsed glow discharge",Spectrochim. Acta B,63, 630, 2008.

[17] J. F. Ziegler, J. P. Biersack and M. D. Ziegler, "SRIM- the Stopping and range of ions in matter", SRIM Co., ISBN 0-9654207-1-X, 2008. 


\section{Military Technical College \\ Kobry Elkobbah, \\ Cairo, Egypt \\ April 3-5,2018}

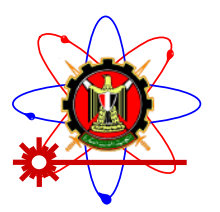

9th International Conference on Mathematics and

Engineering Physics (ICMEP-9)

[18] J. F. Ziegler, M. D. Ziegler, J. P. Biersack, "SRIM - the stopping and range of ions in matter", Nucl. Instr. Meth. Phys. Res. B, 268,11-12, 1818, 2010.

[19] J. F. Ziegler and J. P. Biersack, "The Stopping and Range of Ions in Matter", in, volumes 2 - 6, Pergamon Press, http://www.srim.org, 1985.

[20] J.S. Townsend,"The theory of ionization of gases by collision", Constable,London, 1910.

[21] D. Maric, M. Savic, J. Sivos, N. Skoro, M. Radmilovic-Radjenovic, G. Malovic and Z. Lj. Petrovic, "Gas breakdown and secondary electron yields", Eur. Phys. J. D, 68, 155, 2014.

[22]A. Von Engel , "Electric Plasmas: their nature and uses", Taylor \& Francis, London, 1983.

[23] M. A. Hassouba, F. F. Elakshar and A. A. Garamoon, "Measurements of the breakdown potentials for different cathode materials in the Townsend discharge", Fizika A., 11, 81, 2002.

[24] B. H. P. Broks, W. J. M. Brok, J. Remy, J. J. A. M. van der Mullen, A. Benidar, L. Biennier, and F. Salama, "Numerical investigation of the discharge characteristics of the pulsed discharge nozzle," Phys. Rev. E, Stat. Phys. Plasmas Fluids Relat. Interdiscip. Top., 71, 2005 